\section{Pesquisa pioneira recupera casos de Aids no Estado de São Paulo: integração das bases do Sinan-Aids e da Fundação Seade}

\section{Bernadette Cunha Waldvogel $^{\star}$}

No início do terceiro milênio, a Aids representa, ainda, um sério problema de saúde pública, mas o conhecimento adquirido durante 25 anos desde o seu aparecimento, aliado aos tratamentos mais recentes e eficientes, mantém esta epidemia sob razoável controle em algumas partes do mundo. A observação empírica de casos notificados e de óbitos por Aids revela tendência decrescente no Estado de São Paulo, após 1996, o que consolida a reversão na trajetória da doença até então, além de indicar que o cenário mais promissor visualizado no final do século $X X$ deve firmar-se no período atual.

A obrigatoriedade de notificação dos casos de Aids no Brasil passou a vigorar em 1986, mas a exata dimensão dos casos existentes nos primeiros anos de epidemia ainda não está adequadamente esclarecida.

Com o propósito de melhorar a qualidade das informações produzidas sobre a epidemia da Aids no Estado de São Paulo, a Vigilância Epidemiológica do Programa Estadual DST/Aids (VE-PEDST/Aids), da Secretaria de Estado da Saúde, e a Fundação Sistema Estadual de Análise de Dados - Seade, da Secretaria de Economia e Planejamento do Estado de São Paulo, estabeleceram uma parceria para a realização de um projeto pioneiro no Brasil, com a finalidade de recuperar todos os casos de Aids ocorridos no Estado. Esta recuperação baseou-se nas informações coletadas e processadas pelo Seade, nas declarações de óbito em que houve menção de Aids entre as causas de morte, desde o início da epidemia na década de 80 , até o presente momento. Contando com financiamento da Unesco, por intermédio do Programa Nacional DST/Aids do Ministério da Saúde, identificaram-se os óbitos por Aids, que foram relacionados ao banco de casos notificados de Aids no Estado de São Paulo, possibilitando, assim, informar o óbito para os casos que já estavam notificados e, também, notificar o caso a partir do óbito que não havia sido informado.

A VE-PEDST/Aids e a Fundação Seade firmaram, em 2004, um Convênio de Cooperação Técnica para dar continuidade a esta importante iniciativa de implantação de uma rotina automatizada de relacionamento entre os casos notificados e os fatais de Aids, no sentido de agilizar e aperfeiçoar os instrumentos de acompanhamento desta doença no Estado. Assim, com a riqueza de informações geradas, que permitem a análise conjunta da morbidade e da mortalidade, ficam fortalecidos os programas de monitoramento da epidemia, cujos dados vão subsidiar as ações de tratamento e prevenção da Aids. Isto representa um avanço no conhecimento da evolução da doença no Estado de São Paulo e uma otimização dos esforços despendidos pelos dois órgãos estaduais envolvidos nesta parceria, visando, principalmente, a melhoria da qualidade de vida e de saúde da população paulista.

A Fundação Seade realiza, mensalmente, uma pesquisa nos Cartórios de Registro Civil de todos os municípios do Estado de São Paulo, coletando informações sobre o registro legal dos eventos vitais: nascimentos, óbitos e casamentos. Esse levantamento, realizado desde o final do século XIX, considera dois tipos de

\footnotetext{
${ }^{1}$ Coordenadora do projeto. Gerente de Indicadores e estudos populacionais da Fundação Seade.

Também fazem parte do projeto: Lilian Cristina Correia Morais (Fundação Seade), Margarete Silva Jordani (Fundação Seade), Glauber Ferreira Cardoso (Fundação Seade), Ione Aquemi Guibu (VE-PEDST/Aids), Angela Tayra (VE-PEDST/Aids) e Naila Janilde Seabra Santos (VE-PEDST/Aids).
} 
instrumentos de coleta: mapas estatísticos, contendo dados específicos dos registros legais; e cópias das declarações de óbito e de nascido vivo. Com o avanço dos recursos da informática, o processamento e a vinculação dos dois instrumentos de coleta de dados foram agilizados, tornando-se possível a complementação das bases de dados produzidas, com todas as informações disponíveis nas duas fontes.

O processamento desses eventos gera bancos de estatísticas vitais que permitem estudos minuciosos da população, como, por exemplo, o acompanhamento contínuo da mortalidade por Aids. Cabe ressaltar que os dados do Sistema de Estatísticas Vitais da Fundação Seade são enviados para a Secretaria de Estado da Saúde, integrando, a seguir, o Sistema de Informações sobre Mortalidade (SIM) e o Sistema de Informações sobre Nascimento (Sinasc), coordenados pelo Ministério da Saúde.

Por sua vez, a VE-PEDST/Aids responde pela coordenação das ações de vigilância epidemiológica e pelo gerenciamento dos dados de Aids, no Sistema de Informações de Agravos de Notificação Sinan. Entre suas atribuições, estão o dimensionamento e a caracterização dos casos de Aids ocorridos no Estado de São Paulo. Procurando ampliar esse universo, a VE-PEDST/Aids pesquisou, em um primeiro momento, os óbitos ocorridos no Município de São Paulo. Em 1997, como parte de um trabalho desenvolvido com a Fundação Seade, a pesquisa nas informações das declarações de óbito foi expandida para todos os municípios paulistas.

Com base nas informações das declarações de óbitos em que a Aids constava como causa de morte, era desencadeada uma investigação nos serviços de saúde de ocorrência destes óbitos. Após esse procedimento, os casos poderiam ser enquadrados em um dos critérios de definição de caso de Aids e, se não houvesse retorno da investigação, seriam notificados pelo critério de Declaração de Óbito.

No início, esse trabalho era feito da seguinte forma: a Fundação Seade providenciava fotocópias das declarações de óbitos em que a Aids aparecia como causa de morte e as encaminhava à VE-PEDST/ Aids, que verificava se estes casos já estavam incluídos no banco de notificação. Se constassem do banco, atualizava-se o óbito, caso contrário, eram encaminhados para investigação nas Regionais de Saúde ou diretamente nos serviços onde ocorreram os óbitos.

A parceria entre VE-PEDST/Aids e Seade e o desenvolvimento do projeto de pesquisa para recuperar todos os casos de Aids a partir do óbito têm contribuído para redução da subnotificação dos casos de Aids e atualização das informações sobre a situação de vida do doente. A substituição do processo manual de relacionamento das informações contidas em cada base de dados, por um processo automatizado, torna mais rápida e eficaz a rotina de vinculação e complementação dos dados produzidos sobre a doença, resultando na melhoria de sua qualidade e dos estudos sobre evolução e tendência da Aids.

A técnica de vinculação de dados adotada neste projeto de pesquisa busca encontrar registros referentes à mesma pessoa, que estão tanto no banco de óbitos por Aids como naquele de notificação da doença, comparando campos selecionados e verificando se são idênticos, tais como: nome do doente; nome da mãe; e data de nascimento. Também são comparadas outras variáveis disponíveis, procurando, assim, localizar o maior número possível de pares, ao identificar registros referentes à mesma pessoa e escritos com ortografia diferente nas duas bases de dados.

A variável nome não costuma ser utilizada em pesquisas estatísticas, mas para a técnica de vinculação de bases de dados é importante, principalmente se estas apresentam poucas variáveis em comum. Incluíram-se, então, na base de óbitos utilizada para a vinculação, os campos nome do falecido e nome da mãe, que foram coletados nas declarações de óbito originais existentes no acervo demográfico do Seade.

As atividades englobaram desenvolvimento de programas especiais, em microcomputador, para digitação dos campos adicionais na base de dados de óbitos, compatibilização das variáveis nas duas bases 
de dados, uniformização dos nomes nas duas bases, vinculação dos bancos e formação dos pares selecionados. Foi possível, então, elaborar a base integrada de casos notificados e daqueles fatais de Aids, com a complementação das variáveis disponíveis.

\section{Primeiros resultados da pesquisa}

A pesquisa realizada com a técnica de vinculação de dados entre a base do Seade e a do Sinan-Aids, além de revelar o universo mais completo de casos da doença e complementar as informações disponíveis em cada base individualizada, permite avaliar a cobertura dos casos de Aids no Sinan e identificar aqueles notificados em que não há informação de óbito nesta base, apesar da existência de seu registro na do Seade.

No momento em que foi realizado o relacionamento entre os dois bancos de dados, a base de notificação de Aids contava com 117.629 casos, correspondentes ao período entre o início da década de 80 e fevereiro de 2003, e a base de óbitos totalizava 73.198 casos fatais desta doença, com os campos detalhados incorporados ao banco, referentes ao intervalo temporal de 1985 a 2002.

O processo de vinculação dos dois bancos de dados identificou, em uma primeira fase, 38.981 casos com todas as variáveis vinculadas exatamente idênticas. O restante dos pares gerados, que apresentaram alguma divergência nos campos relacionados, foram para análise da equipe formada pelo Seade e o VE-PEDST/Aids, sendo definidos mais 23.364 pares vinculados.

Foram identificados, então, 62.345 pares de casos de Aids entre as duas bases de dados, ou seja, dos casos fatais pertencentes à base de óbitos do Seade, $85,2 \%$ foram localizados na base de casos notificados do Sinan.

Um número expressivo de casos fatais, entretanto, não estava notificado no banco do Sinan: 10.853 óbitos por Aids, o que representa $14,8 \%$ do total de óbitos da base do Seade e $9,2 \%$ dos casos notificados do Sinan.
Outro resultado importante é avaliar a informação sobre a situação dos doentes notificados. Do total de pares vinculados, $79,8 \%$ apresentavam óbito já notificado no Sinan e data da morte coincidente nas duas bases; $9,2 \%$ registravam datas de óbito divergentes; e em $11 \%$ o óbito não fora informado à VE-PEDST/Aids.

Vale a pena ressaltar que uma parcela dos óbitos informados e com datas idênticas é conseqüência do trabalho de relacionamento manual realizado anteriormente pelas instituições parceiras. A rotina automatizada que está sendo implantada pelos dois parceiros, no Convênio de Cooperação Técnica firmado em 2004, aprimorará, ainda mais, a qualidade das informações contidas no banco integrado de Aids resultante desta parceria.

Os primeiros resultados deste trabalho revelam a importância de se relacionarem as informações contidas em diferentes bases de dados existentes sobre Aids. A vinculação entre os casos fatais e os notificados possibilita conhecimento mais próximo do real número de casos da doença, ampliação do potencial de análise e de cruzamento das variáveis, e estimativa de indicadores de letalidade, sobrevida, diferenciais regionais, por sexo, idade, etc.

No âmbito do Convênio de Cooperação Técnica firmado entre as duas instituições estaduais parceiras, estão sendo realizadas vinculações periódicas entre as bases de dados de óbitos e de casos notificados de Aids, visando atualização contínua do banco integrado resultante, bem como elaboração de estudos aprofundados sobre mortalidade por Aids, sobrevida dos casos da doença, diferenciais segundo categorias de transmissão, gênero, idade e evolução temporal da doença, etc.

\section{Considerações finais}

As bases de dados existentes no SinanAids e no Seade trazem informações muito importantes para o acompanhamento da epidemia. Com a vinculação e a integração de suas informações, que podem ser cruzadas e se complementam, torna-se possível obter uma análise muito mais ampla das 
tendências da Aids, além de aumentar a cobertura dos casos notificados e da situação atualizada do doente.

A principal vantagem dessa integração é a racionalização do uso dos sistemas já existentes, retirando dos mesmos as informações relevantes para um monitoramento mais eficiente da epidemia. O sistema automatizado de vinculação das bases do Seade e do Sinan-Aids permite agilizar a integração dos bancos, mas não dispensa a participação ativa das equipes envolvidas nos dois órgãos estaduais, pois a correta identificação dos indivíduos nas duas bases é indispensável para o acompanhamento de cada caso nos órgãos locais e regionais.

É importante reforçar que um bom sistema de informação - atualizado e confiável - possibilita melhorar o planejamento, a prevenção e a avaliação das ações propostas para o controle de uma doença, como a epidemia da Aids.

Recebido para publicação em 26/05/2006. Aceito para publicação em 09/06/2006. 